\title{
Inducible Nitric Oxide Synthase in Monocytes from Patients with Graves' Disease
}

\author{
Natalia López-Moratalla, Amparo Calleja,* Alvaro González, L. Alberto Pérez-Mediavilla, \\ M. Soledad Aymerich, M. Angeles Burrel, $\dagger$ and Esteban Santiago ${ }^{1}$
}

\author{
Department of Biochemistry, *Department of Endocrinology, and $\dagger$ Department of Cytology and Histology, \\ University of Navarra, Pamplona, Spain
}

Received August 9, 1996

\begin{abstract}
The presence of inducible nitric oxide synthase (iNOS) in fresh monocytes from patients with Graves'disease was demonstrated for the first time. Immunophenotypic analysis showed a profile reflecting a state of activation and differentiation of monocytes. Incubation of lymphomononuclear cells from healthy volunteers in the presence of synthetic peptides with sequences related to thyroid autoantigens (TSH receptor, thyroid peroxidase, or thyroglobulin) led to a stimulation of monocytes manifested by a change in phenotype and expression of iNOS. This expression did not take place on isolated monocytes, unless products associated with Th1 activity were present in the medium. Active peptides contained a characteristic "2-6-11" motif already described [López-Moratalla et al. (1995) Biochim. Biophys. Acta 1265, 181-188]. These results are suggestive of a new role for autoantigens in the pathogenesis of Graves' disease: that of inducing the expression of iNOS and activating the monocyte possibly underlying the autoimmune response. (C) 1996 Academic Press, Inc.
\end{abstract}

Autoantibodies against three major thyroid autoantigens-TSHR, TPO, and Tg — are demonstrable in various thyroid and other autoimmune diseases (1). Autoantibodies against TSHR, in particular, are crucial in the stimulation of the thyroid gland in the hyperthyroidism of Graves' disease (2). The most straightforward explanation of self-ignorance in autoimmune organ specific diseases is that it might be the result of a conventional immune response against self-molecules, for which, under normal circumstances, the need for the establishment of tolerance did not present itself. T cells would ignore autoantigens and remain quiescent (3). However, if a previously activated antigen presenting cell, such as a monocyte, processes proteins in a way that a new or a cryptic epitope is presented, specific autoreactive $\mathrm{T}$ cells would consequently be activated, thus permitting the triggering of an autoimmune response (4). The work here reported was aimed at exploring the expression of iNOS and the state of activation and differentiation of monocytes of patients with Graves' disease, as well as the role that autoantigens could play in this process. We found that synthetic peptides with amino acid sequences pertaining to thyroid autoantigens led to activation and differentiation of monocytes, manifested by a change in phenotype, and expression of iNOS, when lymphomononuclear cells, obtained from healthy individuals, were incubated in the presence of these peptides. The interest of these observations was stressed after the finding that monocytes freshly obtained from patients with Graves' disease contained iNOS already expressed and a high proportion of activated monocyte subsets.

${ }^{1}$ To whom correspondence should be addressed. Fax: (34) 484256 49. E-mail: esantiago@mail2.cti.unav.es.

Abbreviations used: iNOS, inducible nitric oxide synthase; GD, Graves' disease; TSHR, thyrotropin receptor; TPO, thyroid peroxidase; Tg, thyroglobulin; ab, antibody. 


\section{MATERIALS AND METHODS}

Peptide synthesis. Peptides were synthesized by the solid phase method of Merrifield (5), with the Fmoc modification (6).

Cell sources and cultures. Lymphomononuclear cells were obtained from peripheral blood of healthy donors or patients with Graves' desease following the technique described by Bøyum (7). Cells were incubated at $1 \times 10^{6}$ per $\mathrm{ml}$ in RPMI-1640 medium supplemented with $2.5 \%$ of autologous serum, $2 \mathrm{mM} \mathrm{L-glutamine,} \mathrm{penicillin} \mathrm{(100} \mathrm{U/ml)}$ and streptomycin $(100 \mu \mathrm{g} / \mathrm{ml})$ in a $5 \% \mathrm{CO}_{2}$ humidified atmosphere. Isolation of monocytes was carried out taking advantage of their adherence to culture plates. After a period of $6 \mathrm{~h}$ at $37^{\circ} \mathrm{C}$ nonadherent cells were removed with the supernatant followed by three washes with saline solution. Adherent cells, consisting mainly of monocytes (approximately 90 per cent of the cells were $\mathrm{CD}_{1} 4^{+}$), were then carefully detached from the surface of the culture plates by gentle friction.

Immunocytochemistry. The detection of iNOS was carried out as already described (8) using a polyclonal rabbit antibody against mouse macrophage iNOS, kindly provided by V. Riveros-Moreno and S. Moncada (Wellcome Research Labs., Beckenham, Kent, U.K.). The specificity of this antibody for the detection of human inducible NO synthase has been previously shown (9).

Flow cytometry analysis. To determine iNOS in human monocytes murine macrophage FITC conjugated anti-iNOS was used (Transduction Laboratories, Lexington, Kentucky). This is an IgG antibody against a $21 \mathrm{kD}$ protein fragment corresponding to amino acids 961 through 1144 of mouse iNOS. This antibody has already been used in indirect immunofluorescence analysis in order to demonstrate that human mononuclear phagocytes can produce iNOS protein (10). $5 \times 10^{5}$ lymphomononuclear cells were fixed with cold $4 \%$ paraformaldehide for 20 min, then washed with PBS containing $0.1 \%$ sodium azide and suspended in $50 \mu \mathrm{l}$ of permeabilization buffer (PBS with $0.1 \%$ sodium azide, $1 \%$ heat-inactivated FCS and $0.1 \%$ saponin). Cells were incubated at $4{ }^{\circ} \mathrm{C}$ with anti-iNOS antibody (1:50 dilution) or IgGFITC (Becton Dickinson) as control for 45 minutes, washed with permeabilization buffer, suspended in PBS and analyzed by flow cytometry. Fixed cells were analyzed with the EPICS-Profile II (Coulter Electronics, Hialea, FL). $\mathrm{CD}_{14}{ }^{+}$cell surface phenotype was examined by direct staining with labeled antibodies. Monoclonal antibodies CD14 (Leu-M3)-FITC, CD16 (Leu-11a)-PE and anti HLA-DR-PE were from Becton Dickinson. HLA-DR and CD16 antigen expression were measured only on cells that co-stained positively for Leu-M3.

Cytokine determination. Cytokines, TNF $\alpha$, IL-1 $\beta$, IFN $\gamma$, IL-2, IL-5 and IL-4, were measured by quantitative "sandwich', enzyme immunoassay techniques using commercially available kits (Quantikine, R\&D Systems, Minneapolis, US; Genzyme, Cambridge, US). When the incubation was carried out in the presence of anti-HLA-DR antibody, this was added to the wells after the cells to give a final concentration of $2.5 \mu \mathrm{g}$ per ml. Peptide concentration was 30 $\mu \mathrm{g}$ per $10^{6}$ cells.

\section{RESULTS AND DISCUSSION}

Peptides synthesized for this study contained fifteen amino acid residues, fourteen of them representing sequences present in TSHR (11), TPO (12) or Tg (13). An extra valine residue was always added in the $\mathrm{C}$-terminus for convenience of synthesis. The selection of those amino acid sequences was based on the the presence of a structural pattern, which has already been shown to confer on them immunomodulating properties, manifested as activation of monocytes and presentation on HLA-II to Th1 cells $(8,14)$. The following peptides were used: SVTALPSKGLEHLK (peptide P1, residues 237-250 in TSHR); CLCADPYELDDDGR (peptide P2, residues 823-836 in TPO); and QVDAQPLRPCELQR (peptide P3, residues 24-37 in Tg. These peptides had Val or Leu at position 2, Pro at position 6, and Glu or Asp at position 11. A peptide containing a sequence lacking the " $2-6-11$ " motif and present in the TSH receptor, EELKNPQEETLQAF (peptide P4, residues 368-381), was used as negative control.

Adherent cells, mainly monocytes, recovered from the incubated lymphomononuclear population, were processed for immunocytochemical detection of iNOS. The specificity of the immunoreaction was tested by preabsorption of the antiserum anti-iNOS with the synthetic antigenic peptide. Human lymphomononuclear cells from healthy donors were incubated for five days in the presence of each of the peptides related to thyroid autoantigens and containing the "2-6-11" motif, or in the presence of a peptide lacking that motif, as negative control (P4). Adherent cells recovered from the mixed population incubated in the absence of peptides showed no, or very low, immunoreactivity (Fig. 1A). The percentage of immunoreactive cells in six different experiments was always $<10$. A similar picture was obtained if the peptide added had been a negative control (P4). However, monocytes turned immunoreactive, if lymph- 

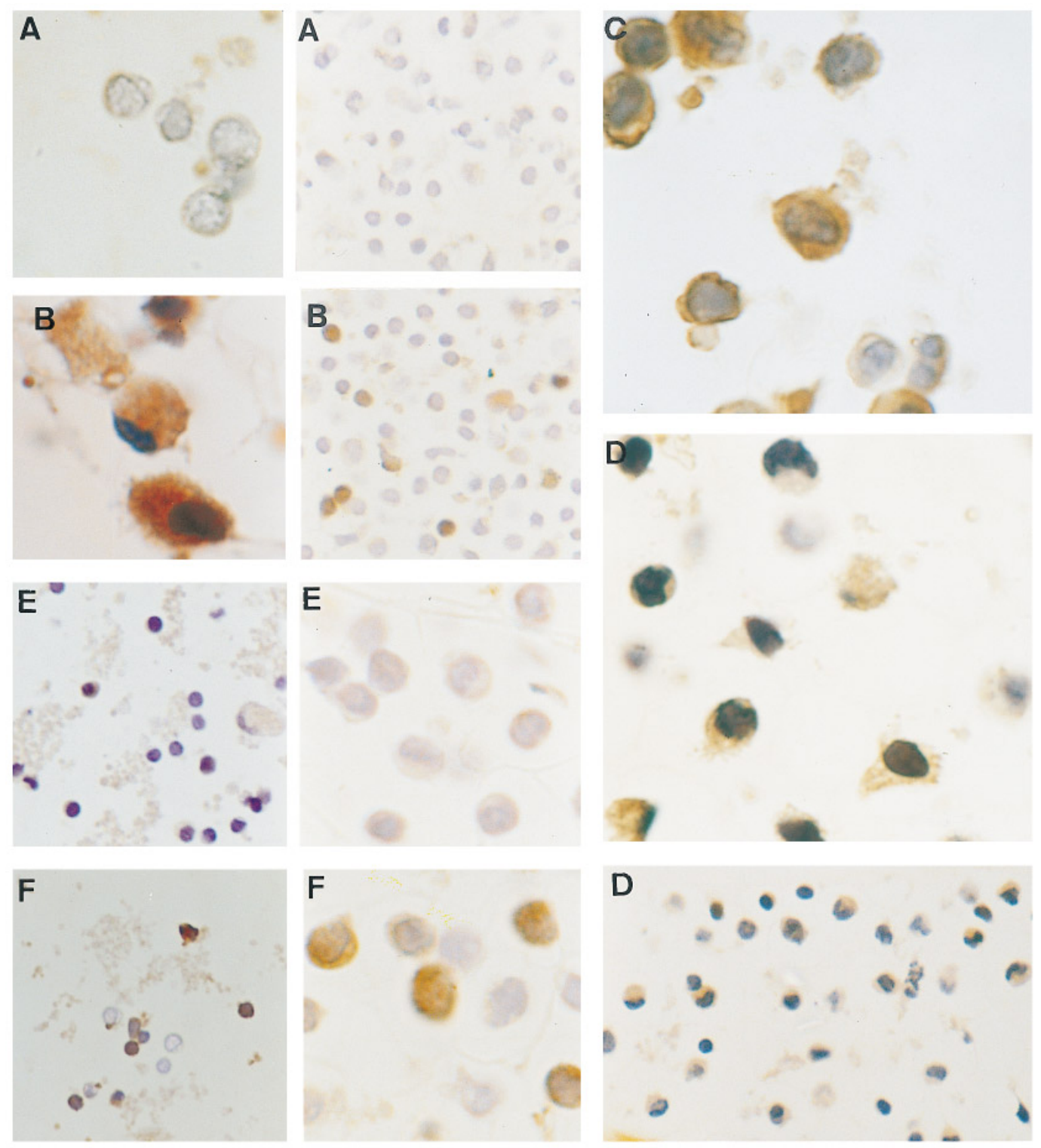

FIG. 1. Inducible nitric oxide synthase in adherent cells demonstrated by immunocytochemistry. (A) Adherent cells recovered from lymphomononuclear cells from a healthy donor incubated in the absence of added peptides. (B) Adherent cells recovered from lymphomononuclear cells obtained from a healthy donor incubated in the presence of active peptide P1. (C, D) Adherent cells recovered from freshly obtained lymphomononuclear cells belonging to two GD patients. Four different patients were studied. In all cases the percentage of immunoreactive cells (brown stain) was always $>75$. (E) Adherent cells (monocytes) from a healthy donor incubated in the presence of active peptide P1; the percentage of immunoreactive cells was always $<15$ in the three cases studied. (F) Adherent cells (monocytes) from a healthy donor incubated with supernatant of lymphomononuclear cells previously incubated with peptide P1. The percentage of immunoreactive cells was $>40$ in the two cases studied.

omononuclear cells had been incubated in the presence of any of the peptides exhibiting the "2-6-11" motif. Figure 1B corresponds to cells incubated with active peptide P1 derived from the TSH receptor. The percentage of immunoreactive cells (brown stain) in five different 
TABLE 1

Cytokines Released by Lymphomononuclear Cells

\begin{tabular}{lccccc}
\hline \multicolumn{1}{c}{ Treatment } & $\begin{array}{c}\text { TNF } \alpha \\
\text { (U/10 cells })\end{array}$ & $\begin{array}{c}\text { IL-1 } \alpha \\
\left(\mathrm{pg} / 10^{6} \text { cells }\right)\end{array}$ & $\begin{array}{c}\text { IL-1 } \beta \\
\left(\mathrm{ng} / 10^{6} \text { cells }\right)\end{array}$ & $\begin{array}{c}\text { IFN } \gamma \\
\left(\mathrm{pg} / 10^{6} \text { cells }\right)\end{array}$ & $\begin{array}{c}\text { IL-2 } \\
\left(\mathrm{pg} / 10^{6} \text { cells }\right)\end{array}$ \\
\hline Healthy donors & & & & & \\
$\quad$ None & $40 \pm 3$ & $15 \pm 2$ & $0.9 \pm 0.2$ & $20 \pm 4$ & $20 \pm 3$ \\
P1 & $190 \pm 8$ & $75 \pm 5$ & $2.5 \pm 0.3$ & $50 \pm 4$ & $85 \pm 9$ \\
P1+anti-DR ab & $520 \pm 35$ & $290 \pm 20$ & n.d. & $18 \pm 3$ & $22 \pm 3$ \\
$\quad$ Anti-DR ab & $500 \pm 40$ & $270 \pm 22$ & n.d. & $20 \pm 3$ & $20 \pm 4$ \\
GD patients & $169 \pm 10$ & $70 \pm 6$ & $2 \pm 0.5$ & $42 \pm 6$ & $70 \pm 9$ \\
$\quad$ None & & & & \\
\hline
\end{tabular}

Results represent the mean of duplicates \pm S.E.M. for 5 independent experiments using cells obtained from the blood of different individuals. Differences between treated cells and control cells were statistically significant $(p<$ 0.001). n.d., not determined.

experiments was $>60$. Freshly isolated monocytes from four different GD patients were all immunoreactive towards iNOS, as evidenced by the specific reaction with the antiserum against the inducible form of the enzyme (Fig. 1C and 1D). The percentage of immunoreactive cells was always $>75$. No staining was observed when sections of cells belonging to healthy individuals were processed under the same conditions. The induction of iNOS was clearly diminished if the incubation of lymphomononuclear cells from healthy subjects with active peptide P1 had been carried out in the presence of anti-HLA-DR antibodies. The percentage of immunoreactive cells was $<25$. When isolated monocytes obtained from normal subjects were incubated in the presence of any of the active peptides for $48 \mathrm{~h}$ no induction of iNOS took place (Fig. 1E). With the purpose of finding out if for iNOS induction to occur a cellto-cell contact between monocytes and $\mathrm{T}$ cells was required, or simply the presence of the cytokines released by $\mathrm{T}$ cells, or both things, we designed the following experiment: freshly isolated monocytes from normal subjects were incubated with the supernatants obtained after the incubation of the lymphomononuclear population belonging to normal subjects under conditions summarized in Table 1 . These cells were incubated in the presence of peptide P1, peptide P1 plus anti-HLA-DR antibody, or anti HLA-DR antibody alone. Table 1 shows that peptide P1 induced the release of monocytic cytokines IL-1 and TNF $\alpha$. Both cytokines were released in larger amounts if anti-HLA-DR antibody was added at the begining of the incubation. However, the release of IL-2 and IFN $\gamma$ induced by peptide P1 was completely blocked by anti-HLA-DR antibody. None of the supernatants contained IL-4 or IL-5. Immunoreactivity towards iNOS was shown by monocytes only when they were incubated with the supernatant obtained in a separate incubation of the whole population of lymphomononuclear cells from healthy donors in the presence of peptide P1 (Fig. 1F). It should be noticed that this was the only supernatant which contained cytokines belonging to Th1 cells. The possibility that other factors could also be present in this supernatant as a consequence of Th1 stimulation cannot be excluded at this stage. It should be noticed that Th1 cells from patients with GD were activated as shown by the spontaneous release of specific cytokines (Table 1). A further confirmation of the cytoplasmic iNOS expression on human monocytes was carried out by means of flow cytometry analysis using murine monoclonal anti-mouse macrophage iNOS. Histograms corresponding to fresh monocytes from GD patients stained with anti-iNOS show a higher fluorescence intensity compared to those obtained with monocytes stained with an irrelevant antibody (Figure 2), indicating a high expression of iNOS. A similar analysis with cells freshly obtained from a healthy donor showed no expression of iNOS. However, iNOS 


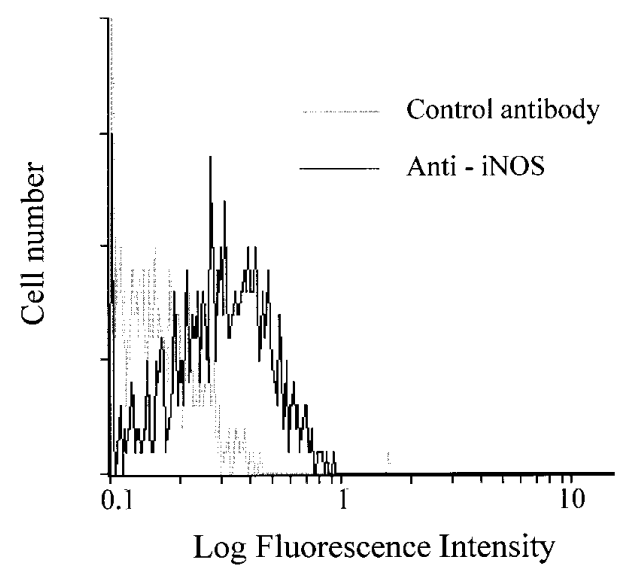

FIG. 2. Flow cytometry analysis of cytoplasmic iNOS expression by monocytes obtained from a patient with Graves' disease. Green fluorescence is shown on the x-axis, as detected by FITC-labelled antibodies, and the arbitrary number of cells is shown on the y-axis. Fresh lymphomononuclear cells were stained using FITC-mouse anti-iNOS or FITC-mouse irrelevant and non-specific IgG as negative control. Monocytes were gated according to light scatter properties. Dotted line histogram shows irrelevant IgG antibody staining; continuous line histogram shows anti-iNOS antibody staining.

was detected if the lymphomononuclear population from healthy donors was treated with peptide P1 (Data not shown).

Evidence is now accumulating that NO is linked to the pathogenesis of autoimmune disease (16). It has been shown that cytokines IL-2 and IFN $\gamma$, produced by Th1 cells, stimulate $\mathrm{NO}_{2}^{-}$production in bone marrow derived macrophages (17), and that cell-cell contacts via MHC class II antigens lead also to NO release (18). Human mononuclear phagocytes can produce iNOS mRNA and protein and, despite that, their ability to generate $\mathrm{NO}$ is very low (10); NO production seems also to depend on the state of maturation of monocytes (19). We have already shown that immunomodulating peptides, capable of stimulating Th1 cells thus causing the release of IFN $\gamma$ and IL-2, induce the expression of iNOS and NO synthesis $(14,8)$. Evidence here reported (Figs. 1 and 2) clearly shows that monocytes freshly obtained from patients with Graves' disease had iNOS already expressed, similarly to what happened with monocytes from healthy subjects stimulated with fragments of thyroid autoantigens (Figs. 1 and 3). Since the addition of anti-HLA-DR antibodies lowered the expression of iNOS, and blocked the release of cytokines by Th1 cells (Table 1), it may be suggested that cytokines or other products released by Th1 cells could be involved in the mechanism of the induction of this enzyme. It is also worth noting that Th1 cells have been implied in Graves' disease (20).

The existence of monocyte subsets differing in their ability to perform certain functions and expression of specific markers led us to carry out a flow cytometry analysis of cells from GD patients. A two-colour immunofluorescence analysis of the monocytes showed that the $\mathrm{CD} 14^{+} \mathrm{CD} 16^{+} \mathrm{DR}^{++}$monocyte subset in ten different patients with GD was approximately four times larger than that found in ten different healthy donors. At the moment of the extraction these patients had circulating antithyroid antibodies. After the incubation of lymphomononuclear cells from healthy subjects in the presence of active peptides derived from thyroid autoantigens for $48 \mathrm{~h}$ the proportion of $\mathrm{CD} 14^{+} \mathrm{CD} 16^{+} \mathrm{DR}^{++}$monocytes increased approximately three times. The expression of HLA-DR on fresh monocytes was higher in patients than in healthy subjects. When the lymphomononuclear population belonging to either patients or healthy subjects was incubated for $24 \mathrm{~h}$ in the presence of 
thyroid peptides a 40-50 per cent rise in HLA-DR expression by cell took place on monocytes. Apparently, the $\mathrm{CD} 14^{+} \mathrm{CD} 16^{+}$monocyte subset with a high expression of HLA-II has its origin in the maturation of $\mathrm{CD} 14^{++}$monocytes (21). A stimulation of human peripheral blood monocytes enhances their ability to mature into cytologically and functionally characteristic veiled/dendritic cells (22); these cells are excellent antigen-presenting cells and play a crucial role in the initiation of normal immune, or autoimmune, responses. Furthermore, other authors (23) have shown that autoimmune thyroiditis can be induced in mice by the transfer of a few dendritic cells pulsed with thyroglobulin.

Finally, one could raise the question on the possibility for autoantigens to encounter circulating monocytes. The presence of a thyroidal m-RNA encoding the ligand-binding region of the human TSHR, but not the transmembrane region, provides the potential for the production of soluble receptors, which could play an important role in autoimmune thyroid disease (24). It has also been reported that TPO can be detected in the blood of normal subjects and of patients with Graves' disease (25). Moreover, anti-Tg specific antibodies have catalytic activity and hydrolyze $\mathrm{Tg}$ (26). Therefore, it would not be surprising that these circulating autoantigens could act as stimuli of blood monocytes.

The results discussed in this report show that patients with Graves' disease presented their circulating monocytes in a state of activation and iNOS expressed, thus markedly deviating from what is usually found in normal subjects. It should be emphasized that a similar state could be induced on monocytes from healthy subjects by fragments of thyroid autoantigens with immunopotentiating properties associated with the "2-6-11" motif. In summary, we suggest that certain fragments of thyroid autoantigens, through their effect on the activation of monocytes and their ability to induce iNOS, could play a crucial role in the initiation, progression and chronicity of Graves' disease.

\section{REFERENCES}

1. Naparstek, Y. (1993) Annu. Rev. Immunol. 11, 79-104.

2. Burman, K. D., and Baker, J. R., Jr. (1985) Endocrinol. Rev. 6, 183-231.

3. Theofilopoulos, A. N. (1995) Immunology Today 16, 90-98.

4. Elson, C. J., Barker, R. N., Thompson, S. J., and Williams, N. A. (1995) Immunology Today 16, 71-75.

5. Merrifield, R. B. (1963) J. Am. Chem. Soc. 85, 2149-2155.

6. Atherton, E., Logna, J. C., and Sheppard, C. R. (1981) J. Chem. Soc. Perkin Trans. 1, 538-546.

7. Bøyum, A. (1983) Scand. J. Immunol. 17, 429-436.

8. Pérez-Mediavilla, L. A., López-Zabalza, M. J., Calonge, M., Montuenga, L., López-Moratalla, N., and Santiago, E. (1995) FEBS Lett. 357, 121-124.

9. Hamid, Q., Springall, D. R., Riveros-Moreno, V., Chanez, P., Howarth, P., Redington, A., Bousquet, J., Godard, P., Holgate, S., and Polak, J. (1993) Lancet 342, 1510-1513.

10. Weinberg, J. B., Misukonis, M. A., Shami, P. J., Mason, S. N., Sauls, D. L., Dittman, W. A., Wood, E. R., Smith, G. K., MacDonald, B., Bachus, K. E., Haney, A. F., and Granger, D. L. (1995) Blood 86, 1184-1195.

11. Libert, F., Lefort, A., Gerard, C., Parmentier, M., Perret, J., Ludgate, M., Dumont, J. E., and Vassart, G. (1989) Biochem. Biophys. Res. Commun. 165, 1250-1254.

12. Kimura, S., Kotani, R., McBride, O. W., Umeki, K., Hirai, K., Nakayama, T., and Ohtaki, S. (1987) Biochemistry 84, 5555-5559.

13. Lejeune, P. J., Mariq, C., Rolland, M., and Lissitzky, S. (1983) Biochem. Biophys. Res. Commun. 114, $73-80$.

14. López-Moratalla, N., Migliacio, M., López-Zabalza, M. J., Pérez-Mediavilla, L. A., and Santiago, E. (1994) Biochem. Biophys. Res. Commun. 205, 2008-2012.

15. Granger, D. L. (1995) Blood 86, 1184-1195.

16. Liew, F. Y. (1994) Immunology Letters 43, 95-98.

17. Cox, G. W., Melillo, G., Chattopadhhyay, U., Mullet, D., Fertel, R. H., and Varesio, L. (1992) J. Immunol. 149, 3290-3296.

18. Hauschildt, S., Bessler, W. G., and Scheipers, P. (1993) Eur. J. Immunol. 23, 2988-2992.

19. Defer, M. C., Dugas, B., Pauleugene, N., Yamaoka, K., Kolb, J. P., and Damais, C. (1995) Life Sciences 317, $1021-1025$.

20. Romagnani, S. (1994) Annu. Rev. Immunol. 12, 227-257. 
21. Ziegler-Heitbrock, H. W. L., Fingerle, G., Ströbel, M., Schraut, W., Stelter, F., Schütt, C., Passlick, B. P., and Pforte, A. (1993) Eur. J. Immunol. 23, 2053-2058.

22. Mooij, P., Simons, P. J., Haan-Meulman, H. J. W., and Drexhage, H. A. (1994) J. Endocrinology $140,503-512$.

23. Knight, S. C., Farrant, J., Chan, J., Bryant, A., Bedford, P. A., and Bateman, C. (1988) Clin. Immunol. and Immunopathology 48, 277-289.

24. Graves, P. N., Tomer, Y., and Davies, T. F. (1992) Biochem. Biophys. Res. Commun. 187, $1135-1143$.

25. Premawardhana, L. D., Kiso, Y., Phillips, D. I., Morteo, C., Furmaniak, J., and Rees-Smith, B. (1993) Thyroid 3, 225-228.

26. Li, L., Tyutyulkova, S., Kazatchkine, M. D., and Kaveri, S. (1995) J. Immunol. 154, 3328-3332. 